http://jmscr.igmpublication.org/home/ ISSN (e)-2347-176x ISSN (p) 2455-0450 crossref DOI: https://dx.doi.org/10.18535/jmscr/v8i1.60

\author{
Journal Of Medical Science And Clinical Research \\ IGM Publication \\ An official Publication of IGM Publication
}

\title{
Original Article \\ Histopathological Study of Colorectal Lesions at Tertiary Care Centre M.Y. Hospital Indore
}

\author{
Authors \\ Dr Rakesh Mehar ${ }^{1}$, Dr Harshul Patidar ${ }^{2 *}$, Dr Meena Mittal ${ }^{3}$, Dr Ashok Panchonia ${ }^{4}$ \\ ${ }^{1,3,4}$ Department of Pathology, M.G.M. Medical College \& M.Y. Hospital, Indore (M.P.), India \\ ${ }^{2}$ Assistant Professor, Department of Pathology, G.M.C. Khandwa (M.P.) and \\ Former S.R. Department of Pathology, M.G.M. Medical College Indore (M.P.), India \\ *Corresponding Author \\ Dr Harshul Patidar \\ Assistant Professor, Department of Pathology, G.M.C. Khandwa (M.P.), India
}

\begin{abstract}
Background: Colon and rectum are affected by various non-neoplastic and neoplastic lesions. Biopsy is essential in many lesions because of delay in diagnosis due to vague symptoms.

Objective: The present study was done to evaluate etiological pattern of colorectal lesions and prevalence of malignant lesions on histopathological examination of biopsies and specimens.

Material and Methods: The present study was conducted in the Department of Pathology, M.G.M. Medical College Indore, from January 2016 to December 2017. Total 104 cases were studied. The diagnosis in all the cases were made on Hematoxylin and Eosin stained slides of processed tissue.

Results: Out of 104 cases, 77 (74\%) were males and 27 (26\%) were females with age range from infant to 80 years. Among 104 cases 18 (17.3\%) shows acute non specific colitis, 10 (9.62\%) shows chronic non specific colitis, $08(7.69 \%)$ shows tuberculosis, 12 (11.56\%) shows ischemic colitis, 05 (4.8\%) shows Juvenile rectal polyp, 07 (6.73\%) shows adenomatous rectal polyp, 12 (11.56\%) Hirschprung's disease, 01 (0.96 \%) shows crohn's disease, 02 (1.92\%) Ulcerative colitis, 04 (3.84\%) shows Haemorrhoids, 17 $(16.34 \%)$ shows adenocarcinoma, 05 (4.80\%) shows mucinous adenocarcinoma, 02 (1.92\%) shows squamous cell carcinoma and $01(0.96 \%)$ shows malignant melanoma.

Conclusion: Majority of cases were non-neoplastic lesions, among which common finding were acute and chronic non specific colitis. Among neoplastic lesions, most common was adenocarcinoma colon. Biopsy is important investigation for diagnosis of malignant colorectal lesions.

Keywords: Colorectal lesions, Acute and chronic non specific colitis, Adenocarcinoma.
\end{abstract}

\section{Introduction}

Colon and rectum are part of large intestine affected by various non-neoplastic and neoplastic lesions. The diseases vary from inflammatory to malignant conditions and many times colonoscopic biopsy is important for confirmatory diagnosis. ${ }^{[1,2]}$
Colorectal cancer is the third most commonly diagnosed cancer worldwide. ${ }^{[3]}$ Acute and chronic non specific colitis, Hirschprung's disease, crohn's disease and ulcerative colitis can cause septicemia and perforation peritonitis. Ischemic colitis may lead to shock and vascular collapse. ${ }^{[4]}$ 


\section{Objective}

The present study was done to evaluate etiological pattern of colorectal lesions and prevalence of malignant lesions on histopathological examination of biopsies and specimens.

\section{Material and Methods}

The present study was conducted in the Department of Pathology, M.G.M. Medical College Indore, from January 2016 to December 2017. Total 104 cases of colon and rectum lesions were studied. The diagnosis in all the cases were made on Hematoxylin and Eosin stained slides of processed tissue.

\section{Results}

Out of 104 cases, 77 (74\%) were males and 27 $(26 \%)$ were females with male preponderance and male to female ratio of 2.8:1. Graph 1 shows gender wise distribution of cases.

Age of the cases ranges from infant to 80 years. Non-neoplastic and benign neoplastic lesions were common in $1^{\text {st }}$ to $3^{\text {rd }}$ decade while malignant lesions were common in $5^{\text {th }}$ to $7^{\text {th }}$ decade.

Table 1 represents, among 104 cases 18 (17.3\%) shows acute non specific colitis, 10 (9.62\%) shows chronic non specific colitis, 08 (7.69\%) shows tuberculosis, 12 (11.56\%) shows ischemic colitis, 05 (4.8\%) shows Juvenile rectal polyp, 07 (6.73\%) shows adenomatous rectal polyp, 12 (11.56 \%) Hirschprung's disease, 01 (0.96 \%) shows crohn's disease, 02 (1.92\%) Ulcerative colitis, 04 (3.84 \%) shows Haemorrhoids, 17 (16.34\%) shows adenocarcinoma, 05 (4.80\%) shows mucinous adenocarcinoma, 02 (1.92\%) shows squamous cell carcinoma and $01(0.96 \%)$ shows malignant melanoma.

Graph 1: showing gender wise distribution of colorectal lesions

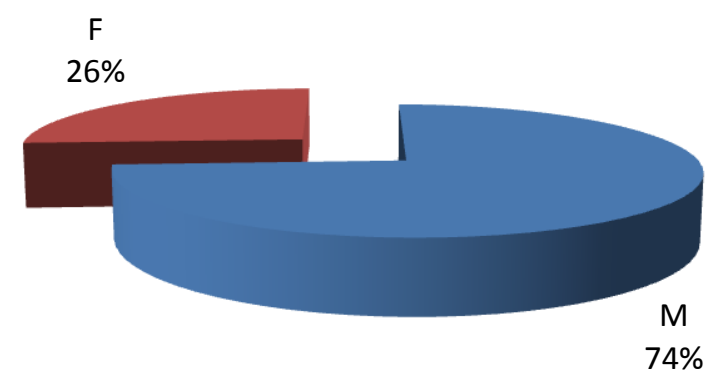

Table 1: showing histopathological distribution of colorectal lesions

\begin{tabular}{|l|l|c|c|}
\hline S.N. & DIAGNOSIS & NO.OF CASES & PERCENTAGE \\
\hline $\mathbf{1}$ & Non-neoplastic lesions & 18 & $17.3 \%$ \\
\hline & Acute non specific colitis & 10 & $9.62 \%$ \\
\hline & Chronic non specific colitis & 08 & $7.69 \%$ \\
\hline & Tuberculosis & 12 & $11.56 \%$ \\
\hline & Ischemic colitis & 12 & $11.56 \%$ \\
\hline & Hirschprung's disease & 01 & $0.96 \%$ \\
\hline & Crohn's disease & 02 & $1.92 \%$ \\
\hline & Ulcerative colitis & 04 & $3.84 \%$ \\
\hline $\mathbf{2}$ & Haemorrhoids & Neoplastic lesions & \multicolumn{2}{|}{} \\
\hline (i) & Benign & 05 & $4.8 \%$ \\
\hline & Juvenile rectal polyp & 07 & $6.73 \%$ \\
\hline & Adenomatous rectal polyp & \multicolumn{2}{|}{} \\
\hline (ii) & Malignant & 17 & $16.34 \%$ \\
\hline & Adenocarcinoma & 05 & $4.80 \%$ \\
\hline & Mucinous adenocarcinoma & 02 & $1.92 \%$ \\
\hline & Squamous cell carcinoma & 01 & $0.96 \%$ \\
\hline & Malignant melanoma & $\mathbf{1 0 4}$ & \\
\hline & TOTAL & & \\
\hline & & & \\
\hline
\end{tabular}




\section{Discussion}

Histopathological examination of colorectal biopsies and specimens is of extremely significance for conclusive diagnosis of nonneoplastic and neoplastic lesions and on the basis of histopathological diagnosis further treatment protocol can be done at the earliest.

This study includes 104 cases of colorectal biopsies and specimens. In our study pattern varied from non-neoplastic lesions like acute \& chronic non specific colitis, tuberculosis, ischemic colitis, rectal polyp, Hirschprung's disease, inflammatory bowel disease and Haemorrhoids to malignant lesions like adenocarcinoma, mucinous adenocarcinoma, squamous cell carcinoma and malignant melanoma.

In our study age group ranged from infant to 80 years with non-neoplastic and benign neoplastic lesions were common in $1^{\text {st }}$ to $3^{\text {rd }}$ decade while malignant lesions were common in $5^{\text {th }}$ to $7^{\text {th }}$ decade, results of malignant lesions were comparable with Ritesh Sulegaon et al. ${ }^{[4]}$

Out of 104 cases, 67 (64.4\%) were non-neoplastic, $12(11.5 \%)$ were benign neoplastic and 25 (24.1\%) were malignant neoplastic cases. The results were comparable with, Sidney J et al ${ }^{[5]}$, R.Teague et al ${ }^{[6]}$ and Rajbhandari $M$ et al ${ }^{[7]}$ in which prevalence of the non-neoplastic lesions were maximum.

In our study $24.1 \%$ cases were malignant lesions, out of which $88 \%$ were adenocarcinoma, these results were comparable with Dr Ambreen Beigh et.al ${ }^{[8]}$ where $94.6 \%$ were adenocarcinomas.

\section{Conclusion}

Majority of cases were non-neoplastic lesions, among which common finding were acute and chronic non specific colitis. Among neoplastic lesions, most common was adenocarcinoma colon. Biopsy is important investigation for diagnosis of malignant colorectal lesions. So this study highlights the significance of histopathology for conclusive diagnosis in colorectal lesions.
Funding: None

Competing Interest: None Declared.

\section{References}

1. Qayyum A, Sawan AS. Profile of colonic biopsies in King Abdul Aziz University Hospital, Jeddah. J Park Med Assoc 2009 Sep;59(9):608-11.

2. Liu C, Crawford JM. The Gastrointestinal tract. In: Kumar, Abbas, Fausto, editors. Robbins and Cotran Pathologic Basis of Disease. 7th ed. Philadelphia. Saunders; 2004. Pp.797-876.

3. Colorectal Cancer Statistics, 2017 CA: Cancer J Clin doi: 10.3322/caac.21395.

4. Ritesh Sulegaon et al., Histological Spectrum of Large Intestinal Lesions with Clinicopathological Correlation, Journal of Clinical and Diagnostic Research. 2015 Nov, Vol-9(11): EC30-EC34

5. Sidney J, Sheldon D Leidner et al. Colonoscopic Biopsy and Cytology in the diagnosis of colon cancer. Cancer 1973;42:2849-53.

6. Teague RH, Salman PR, Read AE. Fiberoptic examination of the colon: a review of 255 cases. Gut,1973;14:139-142.

7. Rajbhandari M, Karmacharya A, Khamal K, Dhakal P, Shreshtha R. Histomorphological profile of colonoscopic biopsies and pattern of colorectal carcinomas in Kavre district. Kathmandu Univ Med J 2013; 43(3):196200.

8. Dr Ambreen Beigh et.al / Spectrum of Colorectal Lesions on Colonoscopic Biopsies; a Histopathological Study in a Tertiary Care Hospital; International Journal of Medical Science and Clinical Inventions, vol. 4, Issue 3, March, 2017. 